\title{
Verocytotoxin-producing Escherichia coli (VTEC) 0157 and other VTEC from human infections in England and Wales: 1995-1998
}

\author{
G. A. WILLShAW, T. CHEASty, H. R. SMITH, S. J. O'BRIEN* and G. K. ADAK* \\ Laboratory of Enteric Pathogens, Division of Gastrointestinal Infections, Central Public Health Laboratory and \\ * Communicable Disease Surveillance Centre, London NW9 5HT
}

\begin{abstract}
A total of 3429 isolations of verocytotoxin-producing Escherichia coli 0157 (VTEC O157) was confirmed from human sources in England and Wales during the period 1995-1998. The largest annual total was 1087 in 1997. Most infections occurred in the third quarter of each year. The overall rate of infection ranged from 1.28 to $2.10 / 100000$ population and showed regional variation. The highest incidence was in children aged 1-4 years. Annually, between $5 \%$ and $11 \%$ of strains were from patients who had travelled abroad. There were 67 general outbreaks of infection represented by 407 (11.9\%) VTEC 0157 isolates. Outbreaks involved transmission by contaminated food or water, person-toperson spread and direct or indirect animal contact, and five were associated with foreign travel. The majority $(\mathbf{7 6} \%)$ of strains carried verocytotoxin (VT) 2 genes and $23.3 \%$ were VT1+VT2. Most strains had the flagellar antigen $\mathrm{H} 7$, but $c$. $14 \%$ were non-motile. Approximately $20 \%$ of isolates were resistant to antimicrobial agents, predominantly streptomycin, sulphonamides and tetracycline. In addition to VTEC O157, strains of serogroup 0157 that did not possess VT genes were identified. These were either derivatives of VTEC 0157 that had lost VT genes or were strains with $H$ antigens other than $\mathrm{H} 7$ that have never been associated with VT production. Strains of VTEC other than 0157 were characterised. Most were associated with diarrhoea, bloody diarrhoea or haemolytic uraemic syndrome and had virulence markers in addition to VT.
\end{abstract}

\section{Introduction}

Verocytotoxin-producing Escherichia coli 0157 (VTEC O157) are associated with human disease including mild diarrhoea, severe bloody diarrhoea with abdominal pain and, in up to $10 \%$ of cases, haemolytic uraemic syndrome (HUS) $[1,2]$. The organism causes sporadic and epidemic infections. The largest outbreak in the UK occurred in Central Scotland in 1996, resulting in $>500$ cases and 21 deaths [3]; a series of related outbreaks in Japan in 1996 involved $>10000$ cases $[4,5]$. Although $\mathrm{O} 157$ is the most important VTEC serogroup, $>100$ serotypes of $E$. coli have been shown to produce verocytotoxin(s) (VT). Some nonO157 VTEC have been associated with outbreaks of infection [6-9].

Transmission of VTEC O157 to man occurs mainly by

Date received 1 Feb. 2000; revised version received 9 June 2000; accepted 11 June 2000.

Corresponding author: Dr G. A. Willshaw (e-mail: gsmith@phls.nhs.uk). consumption of contaminated food, including undercooked beef and meat products, unpasteurised milk and ready-to-eat products including cooked meats and vegetables that have been contaminated [2]. Healthy cattle are the main reservoir of the organism, but it is also carried by sheep and other animals $[10,11]$. Direct or indirect contact with animals provides an alternative route by which infection is acquired [12-16] and person-to-person transmission of the organism occurs in families and institutional settings such as day nurseries and nursing homes [17-20].

The importance of disease due to VTEC O157 and other VTEC has been increasingly recognised [21-23]. Surveillance of VTEC-associated infection is now undertaken by several countries in the European Community and elsewhere, although the criteria and methods applied vary. Since the last detailed report of laboratory surveillance in England and Wales [18] there has been a rise in the number of infections caused by VTEC O157 and in the number of outbreaks. This study reports the continued laboratory surveillance of VTEC O157 in England and Wales from 1995 to 1998. 


\section{Materials and methods}

\section{Isolation of E. coli O157 in diagnostic laboratories}

Stool samples from patients with diarrhoea, bloody diarrhoea and haemolytic uraemic syndrome were examined for E. coli $\mathrm{O} 157$ by National Health Service (NHS), Public Health Laboratory Service (PHLS) and private laboratories in England. In Wales, testing of all first-time acute stool samples for E. coli $\mathrm{O} 157$ has been performed since 1990 [24]. During investigation of sporadic infections and outbreaks, stools from asymptomatic contacts were sometimes tested for carriage of $E$. coli O157. Faecal samples were plated on Sorbitol MacConkey agar (SMAC), or SMAC containing cefixime $0.05 \mathrm{mg} / \mathrm{L}$ and potassium tellurite $2.5 \mathrm{mg} / \mathrm{L}$ (CTSMAC) and putative E. coli $\mathrm{O} 157$ were identified as sorbitol non-fermenting colonies after incubation for $18 \mathrm{~h}$ at $37^{\circ} \mathrm{C}[25,26]$. Colonies were tested for agglutination with anti-O157 serum or anti-O157 latex agglutination kits and identified biochemically as presumptive $E$. coli with commercially available tests before referral to the Laboratory of Enteric Pathogens (LEP).

\section{Confirmation of VTEC O157}

Isolates received by LEP were confirmed biochemically as E. coli and serotyped [27]. Resistance to antimicrobial agents was determined by an agar dilution method [28]. The final plate concentrations of the drugs were (mg/L): ampicillin, 8; chloramphenicol, 8; gentamicin, 4; kanamycin, 16; sulphonamide, 64; tetracycline, 8; trimethoprim, 2; furazolidone, 8; nalidixic acid, 16; ciprofloxacin, 0.125 and 1.0. Strains were tested by colony hybridisation for the presence of VT1 and VT2 genes with digoxigenin-labelled DNA probes [29] and with the fluorescein-labelled eaeO157 probe directed against the $\mathrm{C}$-terminal end of the eae gene of VTEC O157 [30]. Some strains confirmed as E.coli $\mathrm{O} 157$ did not hybridise with VT probes and were investigated further by PCR.

\section{Further examination of faecal samples}

Stools from some patients with bloody diarrhoea or HUS did not yield E. coli O157 on primary screening. These faecal samples were sent to LEP to test for low levels of E. coli $\mathrm{O} 157$ not detected by direct plating and for the presence of VTEC belonging to other $\mathrm{O}$ serogroups. Enrichment culture for E. coli $\mathrm{O} 157$ was in trypticase-soy broth containing bile salts and novobiocin for $6 \mathrm{~h}[25,31]$. Immunomagnetic separation (IMS) with anti-O157 beads (Dynal) was performed as described by the manufacturer and beads were plated on CT-SMAC [32]. Sorbitol-non-fermenting colonies were picked, their identity was confirmed and they were tested for the presence of VT genes.

Preliminary evidence of the presence of other VTEC in stools was obtained by PCR. A sweep of growth from
SMAC agar was grown for $2-3 \mathrm{~h}$ in nutrient broth; the culture was boiled and $2 \mu \mathrm{l}$ were added to a multiplex PCR reaction (see below). Specimens with evidence of amplification of VT sequences were re-plated on to MacConkey agar to yield separated single colonies that were replica-plated on to nylon membrane. VT-positive colonies were identified by hydridisation of the filter with a mixture of VT1 and VT2 probes and then picked from the retained master plate [18]. They were confirmed as E. coli, serotyped and tested with individual VT probes.

\section{PCR tests}

A multiplex PCR tested coliform growth from faecal samples for the presence of VT genes and the Cterminal end of the eae gene of E. coli O157. The sequences of the primers for detection of VT were: primer P6, 5' GGCAGATACAGAGGGAATTTCG 3'; primer P7, 5' TGATGATGGCAATTCAGTAT 3'. The product size was $217 \mathrm{bp}$. This PCR detects but does not differentiate VT1 and VT2 and amplifies the VT2, VT2c and VTe gene subtypes. The eae primers that amplified a fragment of $410 \mathrm{bp}$ have been described previously [30]. Although this reaction is not totally specific for O157 VTEC, very few other VTEC serotypes give this product [30]. In the PCR reactions, annealing was at $55^{\circ} \mathrm{C}$ and extension at $72^{\circ} \mathrm{C}$. Products were separated on agarose $2 \%$ gels [33].

\section{Tests on VTEC of serogroups other than O157}

Confirmed VTEC strains that belonged to serogroups other than 0157 were tested by DNA probing for the presence of the eae gene [34] and for sequences associated with enterohaemolysin production [35].

\section{Analysis of data}

VTEC O157 strains were received from laboratories in England and Wales and confirmed in LEP as E. coli O157 that encoded a verocytotoxin. Isolates that were negative for VT genes by probe and PCR were analysed separately. Duplicate cultures from the same individual were discounted. Within family and general outbreaks, all isolates from different patients were included, as were cultures from contacts, even if they were asymptomatic. For seasonality studies, isolates were included by date of receipt in LEP, as the date of onset of infection was not usually known. Laboratories usually sent cultures within 1-3 days of isolation. If a delay was known to have occurred, the date of isolation was obtained and used in the data set. Analysis of geographical distribution was based on the health region of the laboratory sending the culture. Data associated with foreign travel and general outbreaks were based on information received with the cultures sent to LEP and also from reports to CDSC. Differences in the age-specific incidence rates by gender were analysed by a $\chi^{2}$ test. 


\section{Results}

Properties of VTEC O157 strains

From 1995 to 1998, LEP received 3429 VTEC O157 isolates from laboratories in England and Wales (Table $1)$. The annual totals were greater than those previously reported $[17,18]$. The majority of strains $(76 \%)$ carried VT2 genes only; $23.3 \%$ encoded both VT1 and VT2 and VT1-only strains were very rare. All confirmed VTEC 0157 failed to ferment sorbitol in $24 \mathrm{~h}$ on solid medium. They possessed either the flagellar antigen $\mathrm{H} 7$ or were non-motile (Table 1); the proportion of nonmotile $(\mathrm{H})$ isolates over the 4 -year period was c. $14 \%$. DNA hybridisation showed that all the strains possessed the eae gene of VTEC O157.

The total included 39 strains of VTEC O157 isolated in LEP by the IMS technique from 400 stool samples that were negative on direct culture in the sending laboratory. These were from patients with bloody diarrhoea or HUS or were contacts of known cases.

Over the 4-year period, an average of $20 \%$ of VTEC O157 strains (range 17.4-22.8\%) were resistant to one or more antimicrobial agents tested. Drug resistance was a useful epidemiological marker for some VTEC O157 strains $[17,18]$, but had no relevance to clinical infections. The proportion of resistant strains had not increased since 1994, but was higher than that seen in $1992(10.2 \%)$ and $1993(14.5 \%)$ [18]. The resistance profiles (R-types) were limited, with $87 \%$ of strains resistant to $\mathrm{SSu}, \mathrm{SSuT}$ or $\mathrm{SuT}(\mathrm{S}$, streptomycin; $\mathrm{Su}$, sulphonamide; T, tetracycline). Strains resistant to four or more drugs accounted for $1.3 \%$ (range $0.5-2.4 \%$ ) of strains; no more than two strains per year had the same R-type. Resistance to both nalidixic acid and ciprofloxacin was observed for the first time in 1998 in two epidemiologically related cases who had travelled to the Canary Islands.

\section{Epidemiology of VTEC O157 infections}

There was a peak of infection each year in the months of July, August and September (Fig. 1). The incidence of infection was highest in children aged 1-4 years

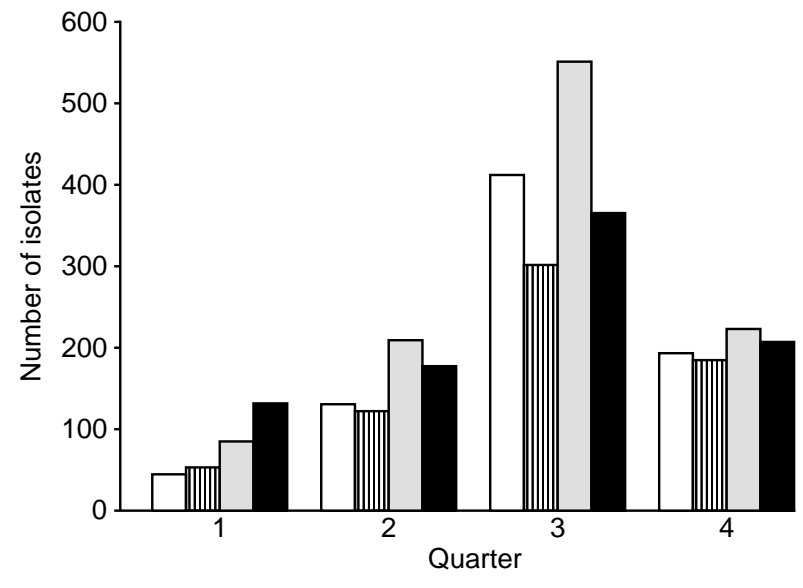

Fig. 1. Quarterly incidence of VTEC O157 in England and Wales, 1995-1998: $\square, 1995$; $\mathbb{L}, 1996$; $\square, 1997$; 1998.

(Fig. 2). Females $>15$ years old were significantly $(\mathrm{p}<0.00001)$ more likely than males to be diagnosed as suffering from VTEC O157 infection. This difference was most marked in the 25-34-year-old and 4559-year-old age groups. VTEC O157 were reported from all regions of England and Wales (Table 2), although the North and South Thames regions had consistently lower incidences. A regional rate exceeded 3/100 000 for the first time in 1997 (Trent region). The regional variation can, in some part, be attributed to outbreaks of infection (see below). A proportion of VTEC O157 infections was linked to foreign travel (Table 3), and in 1997 and 1998 there were general outbreaks of infection associated with travel abroad (see below) especially to Spain, Turkey and Greece.

\section{Outbreaks of infection with VTEC O157}

A minority of VTEC O157 infections was associated with 67 general outbreaks of infection (Table 3), these represented 407 isolates [15, 20,36-40]. Individual outbreaks were small and only six involved $\geqslant 10$ patients; the largest outbreak was in 1995 in North Wales [20]. There was a marked geographical variation in the outbreaks, 28 of which were in two health regions (Table 2). Most outbreaks were in the

Table 1. VTEC O157 from human infections in England and Wales 1995-1998

\begin{tabular}{|c|c|c|c|c|c|}
\hline \multirow[b]{2}{*}{ Year } & \multirow{2}{*}{$\begin{array}{c}\text { Total VTEC } \\
\text { O157 isolates* }\end{array}$} & \multicolumn{4}{|c|}{ Percent of VTEC 0157 isolates that were } \\
\hline & & VT1 & VT2 & $\mathrm{VT} 1+2$ & Non-motile $\left(\mathrm{H}^{-}\right)^{\dagger}$ \\
\hline 1995 & 792 & 0.6 & 80.2 & 19.2 & 15.8 \\
\hline 1996 & 660 & 0.6 & 76.1 & 23.3 & 8.0 \\
\hline 1997 & 1087 & 1.1 & 72.8 & 26.1 & 13.7 \\
\hline 1998 & 890 & 0.7 & 74.7 & 24.6 & 19.3 \\
\hline Total/overall \% & 3429 & 0.7 & 76.0 & 23.3 & 14.4 \\
\hline
\end{tabular}

* Isolates received from laboratories in England and Wales that were confirmed by LEP as VTEC O157. The presence of VT genes was determined by DNA probe [29]. Annual totals for previous years were: 1981 (1); 1982 (1); 1983 (6); 1984 (9); 1985 (30); 1986 (76); 1987 (89); 1988 (49); 1989 (119); 1990 (250); 1991 (361); 1992 (470); 1993 (385); 1994 (411) [17, 18].

†Strains hybridising with at least one VT probe that did not express motility [27]. All other VTEC 0157 had the flagellar antigen H7. 


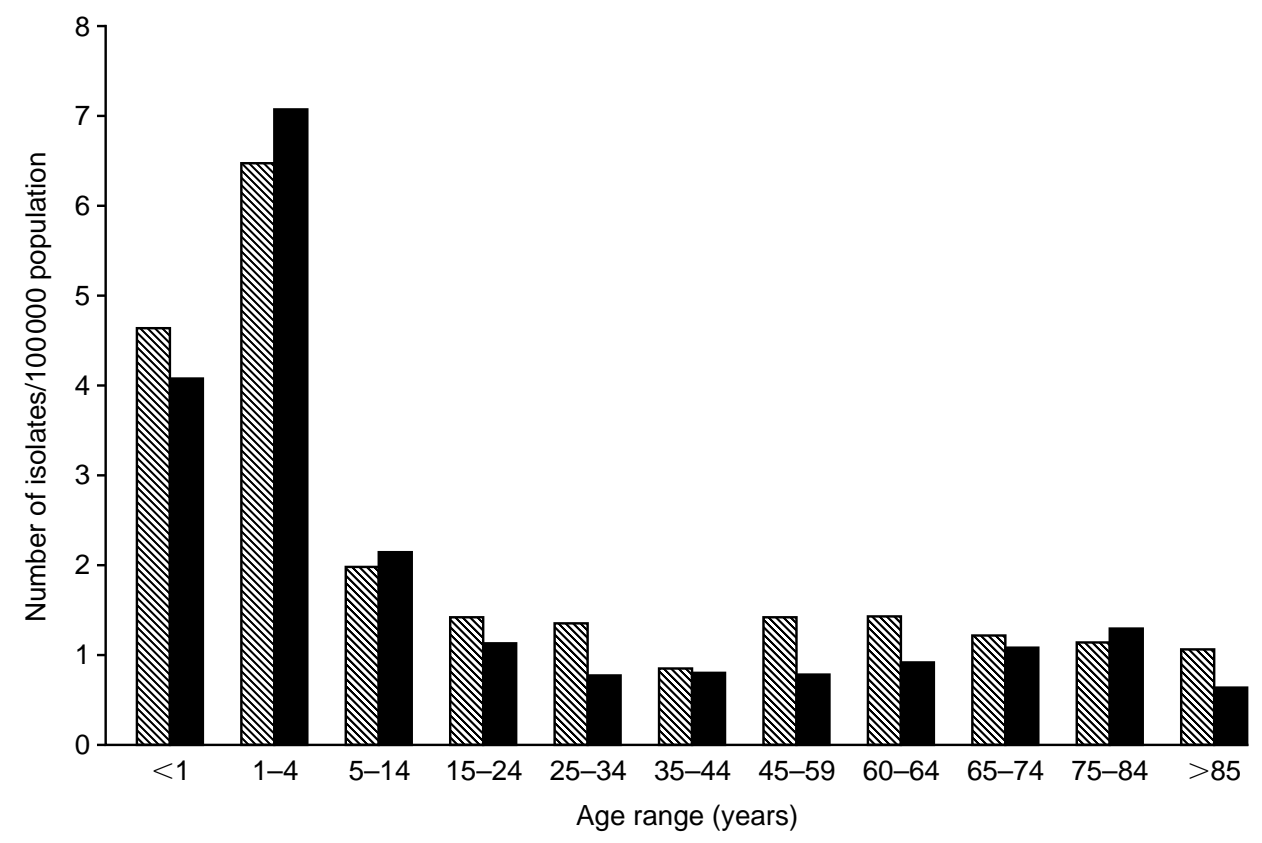

Fig. 2. Rate (/100000) of isolation of VTEC O157 in England and Wales, 1995-1998, analysed by the age and sex $(\mathbb{N}$, female; $\mathbf{\square}$, male) of the patient. For each year, data on patient age and sex were available for between $89 \%$ and $93 \%$ of the total number of strains submitted to LEP.

Table 2. Geographical distribution of VTEC O157 in England and Wales 1995-1998

\begin{tabular}{|c|c|c|c|c|c|c|c|c|c|}
\hline \multirow[b]{2}{*}{ Region } & \multicolumn{2}{|c|}{1995} & \multicolumn{2}{|c|}{1996} & \multicolumn{2}{|c|}{1997} & \multicolumn{2}{|c|}{1998} & \multirow{2}{*}{$\begin{array}{c}1995-98 \\
\text { Outbreaks* }\end{array}$} \\
\hline & $\mathrm{N}$ & Rate & $\mathrm{N}$ & Rate & $\mathrm{N}$ & Rate & $\mathrm{N}$ & Rate & \\
\hline Northern \& Yorkshire & 126 & 1.90 & 109 & 1.64 & 150 & 2.26 & 162 & 2.45 & 16 \\
\hline Trent & 65 & 1.36 & 105 & 2.19 & 156 & 3.25 & 78 & 1.63 & 12 \\
\hline Anglia \& Oxford & 63 & 1.19 & 62 & 1.07 & 113 & 2.13 & 82 & 1.55 & 5 \\
\hline North Thames & 43 & 0.63 & 50 & 0.73 & 94 & 1.37 & 89 & 1.30 & 3 \\
\hline South Thames & 55 & 0.81 & 46 & 0.68 & 71 & 1.05 & 87 & 1.29 & 2 \\
\hline South \& West & 165 & 2.51 & 110 & 1.68 & 162 & 2.47 & 138 & 2.10 & 9 \\
\hline West Midlands & 106 & 2.00 & 57 & 1.07 & 137 & 2.58 & 76 & 1.43 & 6 \\
\hline North West & 88 & 1.33 & 85 & 1.29 & 161 & 2.43 & 115 & 1.74 & 7 \\
\hline Wales & 81 & 2.78 & 36 & 1.23 & 43 & 1.47 & 63 & 2.15 & 1 \\
\hline Annual total/rate & 792 & 1.54 & 660 & 1.28 & 1087 & 2.10 & 890 & 1.71 & $61^{\dagger}$ \\
\hline
\end{tabular}

$\mathrm{N}$, number of isolates. Rates are calculated /100000 using Office of National Statistics population figures for 1995 and are not directly comparable to previously published data for $1992-1994$ because of boundary changes.

*Assigned on the basis of the location of the sending laboratory. One outbreak in the North West region was included in a report on surveillance of VTEC O157 among Welsh residents [47].

${ }^{\dagger}$ There were six additional outbreaks during the 4-year period that involved patients from more than one health region.

Table 3. Association of isolates of VTEC O157 from England and Wales with general outbreaks or foreign travel: 1995-1998

\begin{tabular}{|c|c|c|c|}
\hline Year & Total VTEC O157 & $\begin{array}{l}\text { Number }(\%) \text { associated } \\
\text { with general outbreaks }\end{array}$ & $\begin{array}{c}\text { Number }(\%) \text { associated with } \\
\text { recent foreign travel }\end{array}$ \\
\hline 1995 & 792 & $113 \quad(14.3)$ & $41 \quad(5.2)$ \\
\hline 1996 & 660 & $69 \quad(10.5)$ & $60 \quad(9.1)$ \\
\hline 1997 & 1087 & $153^{*}(14.1)$ & $117^{*}(10.8)$ \\
\hline 1998 & 890 & $72^{\dagger} \quad(8.1)$ & $90^{\dagger} \quad(10.1)$ \\
\hline Total & 3429 & $407 \quad(11.9)$ & $308 \quad(8.9)$ \\
\hline
\end{tabular}

*Includes six isolates from patients included in an outbreak in the Canary Islands [39].

${ }^{\dagger}$ Includes eight isolates from patients included in three separate outbreaks of infection acquired abroad.

community (Table 4) and some were linked to specific restaurants and catering facilities or to consumption of meat from butchers' shops. In at least 27 communitybased outbreaks, transmission was probably through contaminated food or beverages, and in most instances the association was epidemiological. Fourteen outbreaks were in institutional settings including childrens' day nurseries and residential homes for the elderly 
Table 4. General outbreaks of infection with VTEC O157 in England and Wales: 1995-1998

\begin{tabular}{lccccc}
\hline Outbreak setting & 1995 & 1996 & 1997 & 1998 & Total \\
\hline Community & 2 & 6 & 7 & 8 & 23 \\
$\quad$ General & 3 & 4 & 5 & 0 & 12 \\
$\quad$ Restaurant/catering & 2 & 2 & 0 & 0 & 4 \\
$\quad$ Butcher's shop & 2 & 0 & 3 & 3 & 8 \\
Institution & 2 & 1 & 2 & 1 & 6 \\
$\quad$ Hospital/residential & 0 & 1 & 6 & 2 & 9 \\
$\quad$ Nursery/school & 0 & 0 & 2 & 3 & 5 \\
Farm/open farm or animal contact & 11 & 14 & 25 & 17 & 67 \\
Foreign travel & & & & \\
Total & & & & & \\
\hline
\end{tabular}

and involved person-to-person spread (Table 4). Outbreaks linked to 'open' or other farms involved transmission of infection by direct or indirect animal contact. There were five outbreaks in which the VTEC O157 strain was acquired abroad. One of these occurred in Fuerteventura in 1997 and was probably caused by consumption of water from a contaminated well [39]; the others involved travel to Greece (two outbreaks), Majorca (one outbreak) and Lanzarote (one outbreak), but the sources of infection were unknown.

\section{VT-negative isolates of E. coli $O 157$}

From 1995 to 1998, 94 strains were confirmed as E. coli $\mathrm{O} 157$ but were negative for the presence of VT genes by DNA hybridisation and PCR. Thirty-seven of these were sorbitol non-fermenting strains of serotypes O157:H7 or $\mathrm{O} 157: \mathrm{H}^{-}$and possessed the eae gene of VTEC O157. Thus, they had the recognised properties of 'VTEC O157' but lacked VT sequences. Strains of this type made up c. $1 \%$ of the total (3466) sorbitol non-fermenting eaeO157-positive strains (both $\mathrm{VT}^{+}$ and $\mathrm{VT}^{-}$) over the 4 -year period. About $62 \%$ of these strains that appeared to have lost VT genes were from patients with diarrhoea, but none was associated with bloody diarrhoea or HUS. The remaining isolates were from asymptomatic individuals or those whose clinical details were not stated.
The remaining VT-negative strains (57) were negative for the eae $\mathrm{O} 157$ gene and expressed $\mathrm{H}$ antigens other than $\mathrm{H} 7$ or were non-motile or $\mathrm{H}$ untypable. $\mathrm{H}$ antigens identified were $1,3,8,9,10,11,12,16,25,31,34,39$, $40,42,43,45$ and 49, but only the O157:H45 and O157: $\mathrm{H}^{-}$serotypes occurred among VT-negative, eae 0157 -negative strains in each of the 4 years. About $77 \%$ of individuals from whom these strains were isolated had diarrhoea and there were four cases of bloody diarrhoea.

\section{Isolation of VTEC other than serogroup O157}

Table 5 shows the properties of 11 strains of VTEC belonging to serogroups other than $\mathrm{O} 157$ that were either referred as possible causes of sporadic VTECassociated illness or were isolated in the LEP from stools of patients or contacts. Nine patients were symptomatic, including one with HUS and one individual who also carried VTEC O157. An additional isolate was from an asymptomatic child whose parents were infected with VTEC O157 and in one further case clinical details were not stated. Five strains, associated with diarrhoea or HUS were serotype O26:H11.

The strains were examined by DNA probing for virulence markers associated with VTEC (Table 5). Eight strains hybridised with the probe from the

Table 5. VTEC of serogroups other than O157 from human sources in England and Wales, 1995-1998*

\begin{tabular}{|c|c|c|c|c|c|c|c|}
\hline Year & Serotype $^{\dagger}$ & Infection & VT type & eae probe & eae $\mathrm{O} 157$ probe & CVD419 probe & Comments \\
\hline \multirow[t]{4}{*}{1995} & $\mathrm{O} 26: \mathrm{H} 11$ & $\mathrm{D}$ & VT1 & + & - & + & \\
\hline & $\mathrm{O} 26: \mathrm{H} 11$ & $\mathrm{D}$ & VT1 & + & - & + & \\
\hline & $\mathrm{O} 26: \mathrm{H} 11$ & $\mathrm{D}$ & VT1 & + & - & + & \\
\hline & O76:H7 & $\mathrm{BD}$ & VT2 & + & $-\S$ & + & \\
\hline 1996 & $\mathrm{O} ?: \mathrm{H}^{-}$ & $\mathrm{BD}$ & VT1 & + & - & + & \\
\hline \multirow[t]{3}{*}{1997} & $\mathrm{O} 26: \mathrm{H} 11$ & $\mathrm{D}$ & VT1 & + & - & - & \\
\hline & $\mathrm{O} 146: \mathrm{H} 5$ & $\mathrm{D}$ & VT1 & - & - & - & Patient also had VTEC O157 \\
\hline & Orough:H12 & NK & VT2 & + & - & - & \\
\hline \multirow[t]{3}{*}{1998} & $\mathrm{O} 26: \mathrm{H} 11$ & HUS & VT2 & + & - & + & \\
\hline & O118:H12 & None & VT2 & - & - & - & Family contact of VTEC O157 \\
\hline & O128ab:H2 & $\mathrm{BD}$ & $\mathrm{VT} 1+2$ & - & - & + & \\
\hline
\end{tabular}

\footnotetext{
* Includes cultures sent to LEP as putative pathogens from cases of infection; strains isolated in LEP from faecal samples from patients with symptoms consistent with a VTEC infection but from whom an isolate of E. coli O157 had not been made; strains from contacts of O157 VTEC infection.

${ }^{\dagger} \mathrm{O}$ ? indicates that $\mathrm{O}$ antigen could not be identified with currently available antisera. $\mathrm{O}$ rough indicates that smooth colonies could not be obtained for serotype determination.

${ }^{\star} \mathrm{D}$, diarrhoea; BD, bloody diarrhoea; HUS, haemolytic uraemic syndrome; NK, not known.

$\S$ Weak reaction in both probe and PCR tests.
} 
conserved region of the eae gene associated with the formation of attaching and effacing lesions. One of these (O76:H7) also hydridised weakly with the eae $\mathrm{O} 157$ probe, but it did not cross-react with antiO157 serum; it differed phenotypically from VTEC $\mathrm{O} 157$ in that it fermented sorbitol and produced $\beta$ glucuronidase. The majority of the non-O157 VTEC strains hybridised with the CVD419 probe that includes sequences encoding enterohaemolysin.

\section{Discussion}

Isolations of VTEC $\mathrm{O} 157$ by laboratories in England and Wales increased from 1468 during 1992-1994 [18] to 3429 during 1995-1998. While laboratory methods for the isolation of E. coli O157 have improved, particularly with the use of CT-SMAC agar to detect low levels of putative VTEC O157 amongst heavy growth of faecal flora, this was not an attributable cause, as this method is not routinely used in clinical laboratories. However, it did enable the reference laboratory to identify additional VTEC O157 representing c. $1 \%$ of the total. Testing for E. coli $\mathrm{O} 157$ has been broadened with the recommendation that all diarrhoeal stools should be screened [21]. There is an increased awareness of VTEC O157 and pressure to perform tests, particularly since the large outbreak of infection in Central Scotland in late 1996 [3]. The data may reflect a higher disease burden, which is supported by a steady rise in the number of outbreaks $[17,18,41]$ and in reports of VTEC O157 in food animals [11, 42].

As reported previously, young children were most likely to be infected, although the high incidence also reflects the greater likelihood that this group will be taken to a general practitioner for diarrhoeal symptoms. Young children may also have specific risk factors including inadequate personal hygiene, habits such as nail-biting and thumb-sucking and close contact with domestic animals and their food. All these factors have been identified as significant in outbreaks or incidents of infection of young children that have involved transmission by animal contact and person-to person spread $[15,16,20,43]$. Asymptomatic carriage of VTEC O157 has been noted in young children who have been screened as contacts of cases [15], LEP unpublished data]. The marked gender difference for VTEC O157 infection between adult females and males may be because women are more likely than their male counterparts to be involved in food preparation or caring for sick children or other relatives. An important risk factor identified for the development of VTEC O157 infection was care of an existing case [44].

Data on the distribution of VTEC O157 in the regions of England and Wales are difficult to compare with previous findings because administrative changes caused some areas to be merged. Consistently high rates were reported in some regions of relatively higher agricultural activity, particularly involving animals, and lower population density in the North, North-West and South-West [16]. Surveillance varies by region and data may be influenced by the degree to which laboratories pursue follow-up studies and screening of contacts. The South-East of England was always the area of lowest incidence. Differences in regional distribution of VTEC O157 have been reported for Canada [45], Scotland [46] and Wales [47]. Cases associated with foreign travel were found in all regions and are probably an under-estimate of the total of VTEC O157 infections acquired abroad. Travellers may not view mild diarrhoea as unusual and may not seek medical attention unless symptoms are severe or protracted.

The number of outbreaks of VTEC O157 infection increased and involved all three major transmission routes, i.e., foodborne, person-to-person spread and animal contact. The diversity of outbreak settings shows the importance of enhanced surveillance and the recognition of risk factors that may be associated with infection. Of the five outbreaks in 1997 and 1998 associated with travel abroad, four involved fewer than five patients and little epidemiological information was available. Once travellers have returned home, it may be difficult to link apparently sporadic cases from different areas of the country. The outbreak in Fuerteventura [39] affected at least 14 individuals from England, Denmark, Sweden and Finland and demonstrated the value of rapid international communication to identify patients who may be linked to an outbreak.

As in the period 1992-1994, the majority of VTEC O157 in the present study were VT2; however, the contribution of strains with both VT1 and VT2 genes increased to about one-quarter of the total. Demonstration of VT by a biological, antigenic or DNA-based method is essential for the confirmation of VTEC O157. Use of the designation O157:H7 has been increasingly used as synonymous with VTEC O157, but is unreliable. Annually, between $8 \%$ and $19 \%$ of strains from England and Wales were non-motile [18] (Table 1) and reliance on the expression of the $\mathrm{H} 7$ antigen without VT testing will fail to detect significant numbers of strains. A small number of strains that had the $\mathrm{H} 7$ antigen or were non-motile had the biochemical properties of VTEC $\mathrm{O} 157$ and the eae gene characteristic of this organism, but had no evidence of VT genes by probe or PCR tests. VT sequences are located on bacteriophages in some VTEC including O157 and loss of these elements has been reported [48]. The strains appeared to be associated with diarrhoea but not with bloody diarrhoea or HUS. Their pathogenesis may be more closely related to that of the classical enteropathogenic strains of $E$. coli, that possess the attaching and effacing property but do not produce VT [49]. VTnegative $\mathrm{O} 157$ derivatives have been isolated from foods and food animals [LEP, unpublished data] and are probably naturally present in the animal reservoir 
from which they are transmitted to man. Serogroup O157 comprises strains with highly diverse properties $[30,50]$ of which VTEC and their VT-negative derivatives form one group. Among the 57 strains of E. coli $\mathrm{O} 157$ negative for both VT and eaeO157 genes, there were $17 \mathrm{H}$ antigen types but not H7. Some strains of these serotypes have been reported as associated with diarrhoea or extra-intestinal disease $[30,51,52]$ and several have been isolated from cattle and meat surveys [11, 53].

There are no inexpensive simple methods for the routine detection of VTEC other than O157 available in clinical laboratories. Six of the 11 VTEC that were identified belonged to serogroups O26 and O128ab, which are known to cause serious disease [54,55]. Overall, nine strains had genes encoding attaching and effacing lesions or enterohaemolysin production, or both, which are properties commonly present in the subclass of VTEC known as enterohaemorrhagic E. coli (EHEC) associated with bloody diarrhoea and HUS $[1,2]$. Strains that did not have these properties were from an asymptomatic individual or from a mixed infection in which symptoms could have been caused by a VTEC O157 strain.

Infections caused by VTEC O157 have increased in importance in England and Wales, although numbers remain low compared with other gastrointestinal pathogens such as salmonellae and campylobacters [56]. However, the potential severity of disease results in high patient morbidity and significant economic cost. It is essential to maintain and enhance surveillance to identify risk factors and to obtain more evidence on the diversity of transmission routes. This information is essential to implement measures to reduce VTEC O157 infection.

We thank the PHLS and NHS laboratories in England and Wales that submitted cultures and specimens and acknowledge the technical expertise and clerical assistance of colleagues in the LEP. The majority of the data on antimicrobial resistance was provided by Dr J. Threlfall and his staff. We thank Dr B. Rowe, former Director of LEP, for his advice and encouragement.

\section{References}

1. Karmali MA. Infection by verocytotoxin-producing Escherichia coli. Clin Microbiol Rev 1989; 2: 15-38.

2. Griffin PM, Tauxe RV. The epidemiology of infections caused by Escherichia coli $\mathrm{O} 157: \mathrm{H} 7$, other enterohemorrhagic E. coli, and the associated hemolytic uremic syndrome. Epidemiol Rev 1991; 13: 60-98.

3. Ahmed S, Donaghy M. An outbreak of Escherichia coli O157:H7 in Central Scotland. In: Kaper JB, O'Brien AD (eds) Escherichia coli $\mathrm{O} 157: \mathrm{H} 7$ and other Shiga toxin-producing E. coli. Washington, DC, ASM Press. 1998: 59-65.

4. Watanabe H, Wada A, Inagaki Y, Itoh K-I, Tamura K. Outbreaks of enterohaemorrhagic Escherichia coli O157:H7 infection by two different genotype strains in Japan, 1996. Lancet 1996; 348: 831-832.

5. Michino H, Araki K, Minami S et al. Recent outbreaks of infections caused by Escherichia coli O157:H7 in Japan. In: Kaper JB, O'Brien AD (eds) Escherichia coli O157:H7 and other Shiga toxin-producing E. coli. Washington, DC, ASM Press. 1998: 73-81.
6. Caprioli A, Tozzi AE. Epidemiology of Shiga toxin-producing Escherichia coli infections in continental Europe. In: Kaper JB, O'Brien AD (eds) Escherichia coli O157:H7 and other Shiga toxin-producing E. coli. Washington, DC, ASM Press. 1998: $38-48$.

7. Centres for disease control. Outbreak of acute gastroenteritis attributable to Escherichia coli serotype O104:H21 - Helena, Montana, 1994. MMWR Morb Mortal Wkly Rep 1995; 44: 501-503.

8. Kudoh Y, Kai A, Obata $\mathrm{H}$ et al. Epidemiological surveys on Verocytotoxin-producing Escherichia coli infections in Japan. In: Karmali MA, Goglio AG (eds) Recent advances in verocytotoxin-producing Escherichia coli infections (International Congress series no. 1072). Amsterdam, Elsevier. 1994: 53-56.

9. Paton AW, Ratcliff RM, Doyle RM et al. Molecular microbiological investigation of an outbreak of hemolytic-uremic syndrome caused by dry fermented sausage contaminated with Shiga-like toxin-producing Escherichia coli. J Clin Microbiol 1996; 34: 1622-1627.

10. Hancock DD, Besser JE, Rice DH. Ecology of Escherichia coli $\mathrm{O} 157: \mathrm{H} 7$ in cattle and impact of management practices. In: Kaper JB, O'Brien AD (eds) Escherichia coli O157:H7 and other Shiga toxin-producing E. coli. Washington, DC, ASM Press. 1999: 85-91.

11. Chapman PA, Siddons CA, Cerdan Malo AT, Harkin MA. A 1year study of Escherichia coli $\mathrm{O} 157$ in cattle, sheep, pigs and poultry. Epidemiol Infect 1997; 119: 245-250.

12. Shukla R, Slack R, George A, Cheasty T, Rowe B, Scutter J. Escherichia coli $\mathrm{O} 157$ infection associated with a farm visitor centre. Commun Dis Rep CDR Rev 1995; 5: R86-R90.

13. Parry SM, Salmon RL, Willshaw GA et al. Haemorrhagic colitis in child after visit to farm visitor centre. Lancet 1995; 346: 572 .

14. Trevena WB, Willshaw GA, Cheasty T, Wray C, Gallagher J. Vero cytotoxin-producing E. coli $\mathrm{O} 157$ infection associated with farms. Lancet 1996; 347: 60-61.

15. Milne LM, Plom A, Strudley I et al. Escherichia coli O157 incident associated with a farm open to members of the public. Commun Dis Public Health 1999; 2: 22-26.

16. Trevena WB, Willshaw GA, Cheasty T, Domingue G, Wray C. Transmission of Vero cytotoxin producing Escherichia coli O157 infection from farm animals to humans in Cornwall and west Devon. Commun Dis Public Health 1999; 2: 263-268.

17. Thomas A, Chart H, Cheasty T, Smith HR, Frost JA, Rowe B. Vero cytotoxin-producing Escherichia coli, particularly serogroup O157, associated with human infections in the United Kingdom: 1989-91. Epidemiol Infect 1993; 110: 591-600.

18. Thomas A, Cheasty T, Frost JA, Chart H, Smith HR, Rowe B. Vero cytotoxin-producing Escherichia coli, particularly serogroup O157, associated with human infections in England and Wales: 1992-4. Epidemiol Infect 1996; 117: 1-10.

19. Carter AO, Borczyk AA, Carlsson JAK et al. A severe outbreak of Escherichia coli O157:H7-associated hemorrhagic colitis in a nursing home. $N$ Engl J Med 1987; 317: 1496-1500.

20. Al-Jadar L, Salmon RL, Walker AM, Williams HM, Willshaw GA, Cheasty T. Outbreak of Escherichia coli 0157 in a nursery: lessons for prevention. Arch Dis Child 1999; 81: $60-63$.

21. Advisory Committee on the Microbiological Safety of Food. Report on Verocytotoxin-producing Escherichia coli. London, HMSO. 1995.

22. Pennington Group. Report on the circumstances leading to the 1996 outbreak of infection with E. coli O157 in Central Scotland, the implications for food safety and the lessons to be learned. Edinburgh, The Stationery Office. 1997.

23. World Health Organization. Prevention and control of enterohaemorrhagic Escherichia coli (EHEC) infections. Geneva, WHO. 1997: 10-15.

24. Salmon RL, Smith RMM. How common is Escherichia coli $\mathrm{O} 157$ and where is it coming from? Total population surveillance in Wales 1990-1993. In: Karmali MA, Goglio AG (eds) Recent advances in verocytotoxin-producing Escherichia coli infections (International Congress series no. 1072). Amsterdam, Elsevier. 1994: 73-75.

25. Public Health Laboratory Service. Standard Operating Procedures. Investigation of faeces sample for bacterial pathogens. B.SOP30. London, PHLS. 1998. 
26. Zadik PM, Chapman PA, Siddons CA. Use of tellurite for the selection of Vero cytotoxigenic Escherichia coli O157. J Med Microbiol 1993; 39: 155-158.

27. Gross RJ, Rowe B. Serotyping of Escherichia coli. In: Sussman M (ed) The virulence of Escherichia coli: reviews and methods. London, Academic Press. 1985: 345-363.

28. Frost JA. Testing for resistance to antibacterial drugs. In: Chart $\mathrm{H}$ (ed) Methods in practical laboratory bacteriology. Boca Raton, FL, CRC Press. 1994: 73-82.

29. Thomas A, Smith HR, Willshaw GA, Rowe B. Non-radioactively labelled polynucleotide and oligonucleotide DNA probes, for selectively detecting Escherichia coli strains producing Vero cytotoxins VT1, VT2 and VT2 variant. Mol Cell Probes 1991; 5: 129-135.

30. Willshaw GA, Scotland SM, Smith HR, Cheasty T, Thomas A Rowe B. Hybridization of strains of Escherichia coli 0157 with probes derived from the eae A gene of enteropathogenic E. coli and the eaeA homolog from a Vero cytotoxinproducing strain of E. coli O157. J Clin Microbiol 1994; 32 897-902.

31. Hindle MA, Bolton FJ, Wright PA, Durband CA. Improved detection of Verocytotoxin-producing Escherichia coli O157 in faecal samples by enrichment culture. PHLS Microbiol Dig 1995; 12: 71-73

32. Bolton FJ, Aird H. Verocytotoxin-producing Escherichia coli O157: public health and microbiological significance. $\mathrm{Br} J$ Biomed Sci 1998; 55: 127-135.

33. Thomas A, Jiggle B, Smith HR, Rowe B. The detection of Vero cytotoxin-producing Escherichia coli and Shigella dysenteriae type 1 in faecal specimens using polymerase chain reaction gene amplification. Lett Appl Microbiol 1994; 19: 406-409.

34. Jerse AE, Yu J, Tall BD, Kaper JB. A genetic locus of enteropathogenic Escherichia coli necessary for the production of attaching and effacing lesions on tissue culture cells. Proc Natl Acad Sci USA 1990; 87: 7839-7843.

35. Levine MM, Xu J-G, Kaper JB et al. A DNA probe to identify enterohemorrhagic Escherichia coli of O157:H7 and other serotypes that cause hemorrhagic colitis and hemolytic uremic syndrome. J Infect Dis 1987; 156: 175-182.

36. Crampin M, Willshaw G, Hancock $\mathrm{R}$ et al. Outbreak of Escherichia coli $\mathrm{O} 157$ infection associated with a music festival. Eur J Clin Microbiol Infect Dis 1999; 18: 286-288.

37. Gammie AJ, Mortimer PR, Hatch L et al. Outbreak of Verocytotoxin-producing Escherichia coli $\mathrm{O} 157$ associated with cooked ham from a single source. PHLS Microbiol Dig 1996; 13: $142-145$.

38. Stevenson J, Hanson S. Outbreak of Escherichia coli O157 phage type 2 infection associated with eating pre-cooked meats. Commun Dis Rep CDR Rev 1996; 6: R116-R118.

39. Pebody RG, Furtado C, Rojas A et al. An international outbreak of Vero cytotoxin-producing Escherichia coli 0157 infection amongst tourists; a challenge for the European infectious disease surveillance network. Epidemiol Infect 1999; 123: 217-223.

40. Willshaw GA, Smith HR, Cheasty T, Wall PG, Rowe B. Vero cytotoxin-producing Escherichia coli O157 outbreaks in England and Wales, 1995: phenotypic methods and genotypic subtyping. Emerg Infect Dis 1997; 3: 561-565.

41. Wall PG, McDonnell RJ, Adak GK, Cheasty T, Smith HR, Rowe B. General outbreaks of Vero cytotoxin-producing Escherichia coli O157 in England and Wales from 1992 to 1994. Commun Dis Rep CDR Rev 1996; 6: R26-R33.

42. Chapman PA, Siddons CA, Harkin MA. Sheep as a potential source of verocytotoxin-producing Escherichia coli O157. Vet Rec 1996; 138: 23-24.

43. Trevena WB, Hooper RS, Wray C, Willshaw GA, Cheasty T, Domingue G. Vero cytotoxin-producing Escherichia coli O157 associated with companion animals. Vet Rec 1996; 138: 400.

44. Parry SM, Salmon RL, Willshaw GA, Cheasty T. Risk factors for and prevention of sporadic infections with Vero cytotoxin (Shiga toxin) producing Escherichia coli O157. Lancet 1998; 351: 1019-1022.

45. Spika JS, Khakhria R, Michel P, Milley D, Wilson J, Waters J. Shiga toxin-producing Escherichia coli infections in Canada. In: Kaper JB, O'Brien AD (eds) Escherichia coli O157:H7 and other Shiga toxin-producing E. coli. Washington, DC, ASM Press. 1998: 23-29.

46. Reilly WJ. E. coli $\mathrm{O} 157$ in Scotland: an overview. SCIEH Weekly Report 1997; Suppl 97/13: 4-5.

47. Chalmers RM, Parry SM, Salmon RL, Smith RMM, Willshaw GA, Cheasty T. The surveillance of vero cytotoxin-producing Escherichia coli O157 in Wales, 1990 to 1998. Emerg Infect Dis 1999; 5: 566-569.

48. Karch H, Meyer T, Rüssmann H, Heesemann J. Frequent loss of shiga-like toxin genes in clinical isolates of Escherichia coli upon subcultivation. Infect Immun 1992; 60: 3464-3467.

49. Nataro JP, Kaper JB. Diarrheagenic Escherichia coli. Clin Microbiol Rev 1998; 11:142-201.

50. Feng P. Escherichia coli serotype O157:H7: novel vehicles of infection and emergence of phenotypic variants. Emerg Infect Dis 1995; 1: 47-52.

51. Scotland SM, Willshaw GA, Cheasty T, Rowe B. Strains of Escherichia coli O157:H8 from human diarrhoea belong to attaching and effacing class of E. coli. J Clin Pathol 1992; 45: 1075-1078.

52. Schmidt H, Rüssmann, Karch H. Virulence determinants in nontoxigenic Escherichia coli O157 strains that cause infantile diarrhea. Infect Immun 1993; 61: 4894-4898.

53. Willshaw GA, Smith HR, Roberts D, Thirlwell J, Cheasty T, Rowe B. Examination of raw beef products for the presence of Vero cytotoxin producing Escherichia coli, particularly those of serogroup O157. J Appl Bacteriol 1993; 75: 420-426.

54. Scotland SM, Willshaw GA, Smith HR, Rowe B. Properties of strains of Escherichia coli $\mathrm{O} 26: \mathrm{H} 11$ in relation to their enteropathogenic or enterohemorrhagic classification. $J$ Infect Dis 1990; 162: 1069-1074.

55. Willshaw GA, Scotland SM, Smith HR, Rowe B. Properties of Vero cytotoxin-producing Escherichia coli of human origin of serogroups other than O157. J Infect Dis 1992; 166: 797-802.

56. Anon. Trends in selected gastrointestinal infections: 1999. Commun Dis Rep CDR Wkly 2000; 2: 9, 12. 